\title{
Analisis Penyebab Kelongsoran Retaining Wall Workshop PT.MHB KM. 13 Balikpapan
}

\author{
Totok Sulistyo, ST. MT ${ }^{1)}$, Chairil Anwar, SST', \\ ${ }^{1}$ Teknik Sipil, Politeknik Negeri Balikpapan \\ e-mail : totok.sulistyo@poltekba.ac.id, \\ ${ }^{2}$ Teknik Sipil, Politeknik Negeri Balikpapan \\ chairil.anwar@poltekba.ac.id,
}

\begin{abstract}
Research Location, Workshop of PT MHB is located on JL. Soekarno Hatta Km. 13. Research is aimed to investigate root causes of retaining wall failure, and intended to find fact in order could be designed new precised and safe retaining wall.

Field activity was conducted at area of PT. MHB workshop, and Laboratory test was conducted at PT. Geosindo Samarinda. This research involved field observation, topographic mapping, cone penetration test, standard penetration test, undisturb sampling, measurement of soil unit weight, atterberg limit, sieve and hydrometer test, unconfine compression est and direct shear. And virtual simulation was conducted using Geostudio student version and Xstable.

Although in normal condition unsaturated soil has $\gamma=1.75 \mathrm{~g} / \mathrm{cm}^{3}, \phi=16^{\circ}, c=0.296 \mathrm{~kg} / \mathrm{cm}^{2}$ showing safe slope with safety factor 1.63 to 1.64 but in increasing water content $\gamma_{\text {sat }}=2,02 \mathrm{~g} / \mathrm{cm}^{3}$ internal friction angle reaches $0^{\circ}$ and cohesionless where water content reach $56 \%$ safety factor will decreases to 0.452 .

Retaining wall failure phase I occured when water content reached $56 \%$ (saturated condition), so that liquid limit was passed and soil turn to liquid (liquifaction) that caused soil creep and flow and push retaining wall in to failure. Later on in other rainy season while soil naturally more compacted slope become unstabil because increasing water content and unit weight of soil that caused circular landslide with cohession of soil more than zero.
\end{abstract}

Keywords: Factor of Safety, Shearing Resistance, Liquifaction

\section{Abstrak}

Lokasi penelitian adalah Workshop PT. MHB berada di Jl. Soekarno Hatta Km.13. Maksud penelitian menyelidiki penyebab kegagalan retaining wall dengan tujuan agar dapat dilakukan kembali upaya desain ulang retaining wall yang tepat dan aman

Kegiatan penyelidikan lapangan dilakukan di komplek workshop PT. MHB, dan pengujian laboratorium di lakukan di PT. Geosindo Samarinda. Metodologi penelitian yang dipakai adalah: observasi lapangan, pemetaan topografi, cone penetration test, standard penetration test, undisturb sampling, pengukuran berat volume, atterberg limit, sieve and hydrometer test, unconfine compression test dan direct shear. Dan virtual simulation menggunakan Geostudio student version dan Xstable.

Walaupun pada kondisi normal tanah tidak jenuh air mempunyai $\gamma=1.75 \mathrm{~g} / \mathrm{cm}^{3}, \phi=16^{\circ}, c=0.296$ $\mathrm{kg} / \mathrm{cm}^{2}$ menujukan kondisi slope aman FK lokal 1,63 dan FK global 1,64 namun dalam kondisi jenuh air $\gamma_{\text {sat }}=2,02 \mathrm{~g} / \mathrm{cm}^{3}$ gudut geser dalam $\phi$ mendekati $0^{\circ}$ dan kohesi $\mathrm{c}$ mencapai 0 dimana kandungan air mencapai $w=56 \%$ akan terjadi pergeseran nilai FK sampai 0.452 .

Keruntuhan retaining wall phase I terjadi ketika kandungan air mencapai $56 \%$, sehingga batas cair tanah terlampaui dan terjadi liquifaction yang mengakibatkan aliran dan rayapan tanah yang mendorong retaining wall runtuh. Kemudian terjadi longsoran lagi (phase II) disebabkan oleh $\gamma$ tanah yang meningkat akibat air hujan dengan kohesi lebih besar dari 0 , sehingga terjadi longsoran guling yang dicirikan bidang longsor yang berbentuk circular.

Kata Kunci: Faktor Keamanan, Kuat Geser, Liquifaction 


\section{Pendahuluan}

Workshop PT. MHB terletak di Jalan Soekarno-Hatta KM.13, Balikpapan Utara merupakan daerah dengan morfologi berupa perbukitan bergelombang, dimana formasi geologi yang berada dibawahnya merupakan Formasi Kampung Baru dengan ciri lithologi yang didominasi oleh berupa batulempung dan batulanau serta material lempung pasiran dalam kondisi lepas (loose materials), dimana kondisi hidrogeologi pada sebagian daerah lereng merupakan daerah penurapan (discharge area), yang dicirikan oleh exfilltrasi berupa mata air yang keluar pada beberapa muka air tanah yang terpotong oleh lereng (Totok Sulistyo, 2013).

Karena terletak mendekati garis katulistiwa Kota Balikpapan memiliki iklim hujan yang terjadi hampir sepanjang tahun. Curah hujan yang terjadi menyebabkan terjadinya infiltrasi air kedalam pori-pori tanah yang menyebabkan makin meningkatnya berat volume atau beban tanah pada lereng dan menurunkan sudut geser dalam tanah tersebut akibat terlapauninya batas cair. Interaksi semua faktor tersebut seringkali menyebabkan gerakan tanah dan penurunan tanah. Pada bangunan sipil fenomena gerakan tanah tersebut sering menyebabkan kerusakan sampai terjadinya terjadinya bencana. Gerakan tanah atau longsor tersebut juga sering menyebabkan kerugian ekonomi cukup besar karena rusaknya baik infrastruktur maupun suprastruktur yang berada diatasnya.

Untuk penanggulangan yang tepat maka diperlukan langkah awal berupa upaya indentifikasi karakteristik gerakan tanah. Identifikasi tersebut meliputi observasi lapangan, pengujian lapangan (insitu), uji laboratorium dan pemodelan komputer untuk menentukan faktor keamanan secara geoteknikPenelitian diperlukan untuk menarik kesimpulan dari hipotesis gerakan tanah yang terjadi. Selain itu juga dapat diketahui lebih mendalam karakteristik serta genesa gerakan tanah, untuk selanjutnya dapat digambarkan sebagai model dan dapat berguna bagi perencanaan stabilisasi lereng maupun pembangunan bangunan sipil diatas lereng tersebut.

Maksud dari penelitian lapangan berupa investigasi terjadinya keruntuhan lereng dan retaining wall redesign, investigasi dilakukan untuk menemukan akar masalah root cause terjadinya longsoran pada lereng timbunan di workshop PT. MHB KM.13 dengan tujuan mendapatkan fakta dan data agar dapat di lakukan disain retaining wall yang tepat dan aman.

\section{Metode Penelitian}

Kegiatan penyelidikan tanah ini dilakukan di komplek workshop PT. MHB Kawasan Industri Kariangau Jl. Soekarno - Hatta Km 13. Balikpapan. Sedangkan kegiatan pengujian laboratorium di lakukan di Laboratorium PT. Geosindo Samarinda, dan analisis serta pekerjaan studio dilakukan di CV. CM Multi Jaya Balikpapan.

Metodologi pengerjaan yang dilakukan dalam melakukan analisis penyebab kelongsoran dan disain ulang retaining wall ini adalah melalui beberapa tahapan pekerjaan yang dilakukan diantaranya :
a. Pekerjaan Lapangan
b. Uji Laboratorium
c. Pekerjaan Studio.

\section{Pekerjaan Lapangan}

Perkerjaan Lapangan yang meliputi :
a. Observasi lapangan
b. Pemetaan topografi
c. Cone Penetration Test (CPT)
d. Standard Penetration Test (SPT)
e. Undisturb Sampling (UDS)

Field Observation dilakukan untuk mendapakan data visual dilapangan yang 
meliputi arah, diskripsi kelongsoran dan diskripsi tanah sehingga dapat ditarik hipotesa penyebab kelongsoran yang selanjutnya akan diuji melalui uji laboratorium dan simulasi komputer. Field Observation juga merupakan survey awal untuk menentukan lokasi titik CPT dan Bor atau SPT.

Pemetaan Topografi dilakukan untuk mendapatkan peta topografi, dimensi lereng, koordinat dan elevasi serta titik ikat lokasi Bor dan titik CPT.

CPT dilakukan pada empat lokasi dua di bagian atas slope dan dua titik dibagian bawah slope, CPT dilakukan untuk mendapatkan mendapatkan informasi mengenai kondisi, kedalaman lapisan tanah keras dan data daya dukung tanah melalui nilai perlawanan konus dan hambatan lekatnya.

Boring dan SPT dilakukan pada dua titik lokasi pada bagian atas dari lereng dan bagian bawah dari lereng, SPT dilakukan dilakukan dalam interval kedalam tiap dua meter sampai dengan tujuan untuk menentukan relative density atau konsistensi subsoil. Pengujian SPT menggunakan split barrel samplinger untuk mendapatkan ketahanan tanah terhadap penetrasi (nilai-N), menggunakan hamer dengan berat 63.5 $\mathrm{kg}$ yang dijatuhkan setinggi $0.76 \mathrm{~m}$. Dalam proyek ini batasan SPT yang dilakukan adalah sampai mencapai nilai $\mathrm{N}$ lebih besar $60(\mathrm{~N}>60)$ agar didapatkan data subsoil yang mampu untuk mendukung struktur dari retaning wall yang direncanakan.

UDS atau pengambilan contoh tanah tidak terganggu dilakukan dilakukan saat boring dan SPT dengan interval kedalaman setiap empat meter untuk mendapatkan sample tanah tidak terganggu yang representatif.

\section{Uji Laboratorium}

Sampel tanah tidak teganggu hasil UDS dari lapangan kemudian disimpan dalam tabung tertutup dibawa ke laboratorium untuk selanjutnya dilakukan beberapa pengujian berikut:

a. Index properties test yang terdiri dari

- Berat Volume Unit Weight of Soil ( $\mathrm{Y})$

-Atterberg Limit (LL, PL, PI)

- Sieve and Hydrometer Test

b. Engineering properties yang terdiri dari

- Unconfine Compression Test (qu)

- Direct Shear $(c, \varnothing)$

\section{Pekerjaan Studio}

Pekerjaan studio yang dilakukan adalah virtual simulation, dalam simulasi virtual ini dilakukan dengan mempergunakan software komputer untuk mensimulasikan kestabilan lereng dengan input parameter adalah dari hasil uji laboratorium serta geometri lereng yang diperoleh dari sayatan topografi lereng. Melalui simulasi ini software akan melakukan analisis dan menghasilkan ratusan bidang gelincir dan akan menghitung moment penahan dan juga gaya pendorong sehingga akan ditampilkan suatu bidang longsor dengan kondisi paling kiritis atau paling rendah dalam angka safety factor (SF). Software ini juga menghasilkan gambar profil longsoran pada lereng yang dianalisis. Software yang digunakan untuk membantu analisis kestabilan lereng ini adalah software Geoslope dan Xstable.

\section{Hasil Penelitian dan analisis data Hasil Observasi}

Hasil observasi dari pengamatan visual menunjukan bahwa kegagalan lereng slope failure telah terjadi dan menyebabkan terjadinya kegagalan dari retaining wall tipe grafitasi, dimana retaining wall runtuh dan terguling. Longsor ini juga menyebabkan sebagian workshop under carriage PT. MHB mengalami penurunan dan beton lantai patah. Dari hasil pengamatan lapangan apabila dituangkan sket maka diketahui 
telah terjadi kelongsoran lebih dari satu phase. Dengan jenis longsoran pada phase pertama adalah soil creep dengan arah gaya lateral yang dibuktikan oleh arah rebahnya retaining wall serta bukti arah micropile tilting yang miring sejajar dengan slope, dan jenis longsoran pada phase kedua adalah longsoran busur circular landslide yang di indikasikan oleh sebagian workshop yang turun dan arah kemiring pilar beton workshop yang miring berlawanan dengan kemiring dari slope (lihat gambar 3.2).

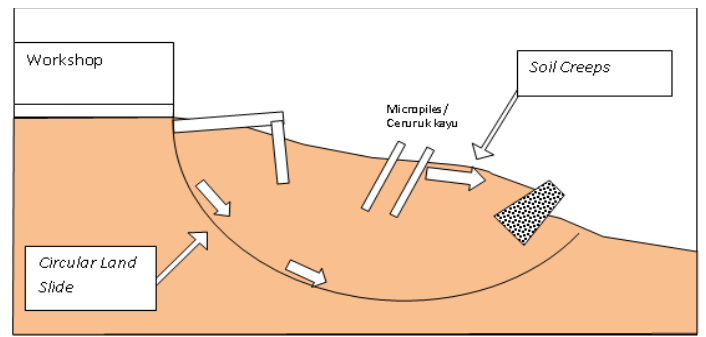

Gambar 3.1. Sket Dua Phase (Soil creeps dan Circular LandSlide) Kegagalan Slope pada Workshop PT. MHB

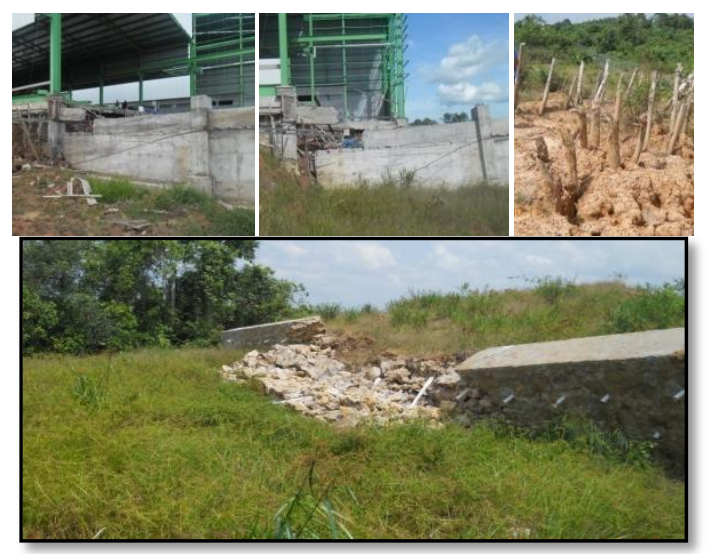

Gambar 3.2. Bukti andanya dua phase kelongsoran Tiang Beton miring kearah yang berlawanan dengan micropile

\subsection{Pengujian lapangan}

\subsubsection{Sondir (CPT)}

Dari hasil pengujian Sondir diketahui lapisan keras berkisar pada kedalaman 10.40 meter pada titik S.01; 8.40 meter pada titik S.02; 8.00 meter pada titik S.03; dan 8.40 meter pada titik S.04. Hasil uji dapat dilihat dalam tabel 3.1 Berikut.
Tabel 3.1. Rekapitulasi hasil Pengujian CPT

\begin{tabular}{|c|c|c|c|}
\hline CPT & $\begin{array}{c}\text { Kedalaman } \\
(\mathbf{m})\end{array}$ & $\begin{array}{c}\text { Cone } \\
\text { Resistance } \\
\left(\mathbf{k g} / \mathbf{c m}^{2}\right)\end{array}$ & $\begin{array}{c}\text { Total } \\
\text { Friction } \\
(\mathbf{k g} / \mathbf{c m})\end{array}$ \\
\hline S.01 & 10.40 & 231.59 & 675.24 \\
\hline S.02 & 8.40 & 222.49 & 599.20 \\
\hline S.03 & 8.00 & 195.19 & 852.25 \\
\hline S.04 & 8.40 & 217.44 & 579.53 \\
\hline
\end{tabular}

\subsubsection{Pemboran dan SPT}

Pengujian Bor dan SPT dilakukan pada dua lokasi yang terletak di bagian atas dari slope (crown) dan bagian bawa dari slope (toe), hasil dari uji boring dan SPT sebagai berikut :

Tabel 3.2. Rekapitulasi Hasil Uji Bor dan

\begin{tabular}{|c|c|c|c|}
\hline No & $\begin{array}{c}\text { Type Soil, } \\
\text { Kedalaman, N- } \\
\text { SPT }\end{array}$ & BH.01 & BH.02 \\
\hline \multirow[t]{3}{*}{1} & Clay (Depth meter) & $\begin{array}{c}0.00- \\
16.00\end{array}$ & $\begin{array}{c}0.00- \\
12.00\end{array}$ \\
\hline & Tickness (meter) & 16.00 & 12.00 \\
\hline & N-SPT & $4-56$ & $5-\geq 60$ \\
\hline \multirow[t]{3}{*}{2} & $\begin{array}{c}\text { Claystone (Depth } \\
\text { meter) }\end{array}$ & $\begin{array}{c}16.00- \\
18.00\end{array}$ & \\
\hline & Tickness (meter) & 2.00 & \\
\hline & N-SPT & $\geq 60$ & \\
\hline
\end{tabular}

\subsection{Pengujian Laboratorium}

Dari pengujian laboratorium dapat dilihat pada tabel 3.3: nilai berat isi $(\mathrm{Y})$ berkisar $1.74-1.83 \mathrm{gram} / \mathrm{cm}^{3}$, liquid limit (LL) berkisar $34.50-45.50 \%$, plastic limit (PL) berkisar 13.96 $23.75 \%$, plasticity Index (PI) berkisar antara 16.45 - 27,42\%, Dari Sieve analisis diketahui kandungan lempung berkisar $39.59-46.73 \%$, lanau berkisar $30.84-40.28 \%$, sand berkisar $14.08 \%$ - 
$24.00 \%$, gravel $0.99-5.57 \%$. Dengan sifat mekanik sebagai berikut unconfined compression (qu) berkisar 0,494-0.670 $\mathrm{kg} / \mathrm{cm}^{2}$, sudut geser dalam $(\varnothing)$ berkisar $15^{\circ}-24^{\circ}$, kohesi (c) berkisar 0.296 $0.482 \mathrm{~kg} / \mathrm{cm}^{2}$.

Tabel 3.3. Rekapitulasi Hasil Uji

Laboratorium

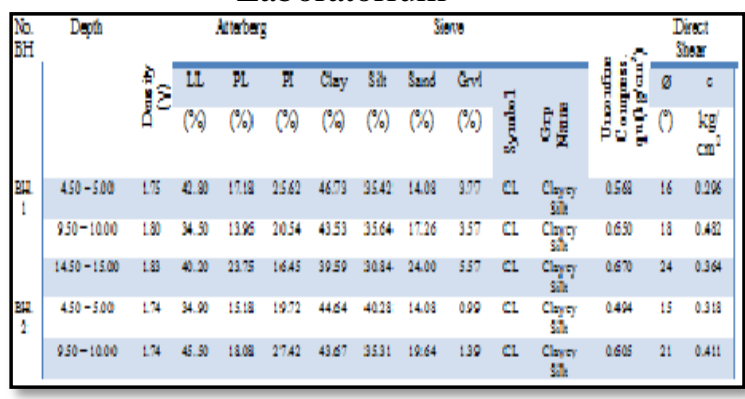

\subsection{Hasil Simulasi Virtual dan Analisis}

Pada Kondisi tanah tidak jenuh air maka didapatkan data index properties dan enginering properties sebagai berikut $\gamma=$ $1.75 \mathrm{~g} / \mathrm{cm}^{3}, \phi=16^{\circ}, \mathrm{c}=0.296 \mathrm{Kg} / \mathrm{cm}^{2}$. Pada kondisi tanah tanah jenuh air maka kondisi tanah akan berubah baik index propertiesnya maupun engineering propertiesnya menjadi $\gamma_{\text {sat }}=\mathbf{2 , 0 2} \mathrm{g} / \mathrm{cm}^{3}$ Sudut Geser dalam $\phi$ mendekati $\mathbf{0}^{\mathbf{0}}$ dan kohesi c mendekati $0 \mathrm{~kg} / \mathrm{cm}^{2}$ dimana kandungan air mencapi $\mathbf{w}=\mathbf{5 6} \%$, hal ini dikuatkan dengan index plastisitas (PI) tanah terkecil mencapai 16,45\% yang dapat memberikan gambaran perubahan tanah dari fase plastis ke cair cukup pendek, hasil simulasi menunjukan bahwa SF dari lereng adalah 0.452 dimana dengan kondisi SF $<1$ dipastikan bahwa lereng pasti runtuh karena SF merupakan perbandingan gaya penahan dengan gaya pendorong

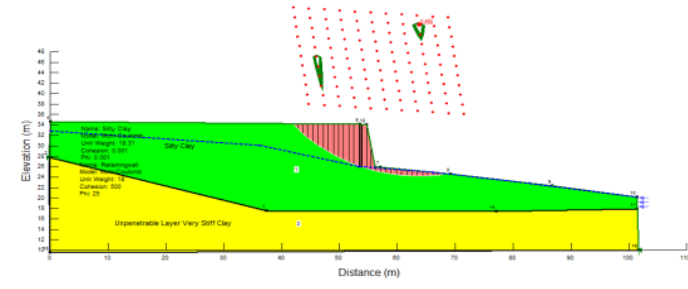

Gambar 3.3. Hasil simulasi komputer terhadap slope pada kondisi jenuh air

Walaupun pada kondisi normal tanah tidak jenuh air menujukan kondisi slope aman dengan SF lokal 1,63 dan SF global 1,64 namun dalam kondisi kandungan air yang meningkat akan terjadi pergeseran nilai SF sampai lebih kecil dari 1. Namun demikian penentuan SF dilakukan berdasarkan kondisi dinamis tanah, karena analisis kestabilan lereng secara statistik tidak tentu maka faktor keamanan tidak dapat diperoleh secara langsung dari kondisi kestimbangan statis (Hang Lin,Wenwen Zhong, Wei Xiong, and Wenyu Tang, 2014).

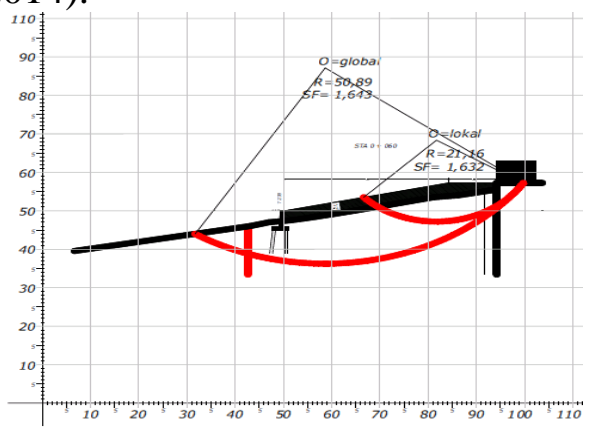

Gambar 3.4. Hasil Analisis pada kondisi normal tidak jenuh air lereng aman SF>1,5

\section{Kesimpulan}

Dari hasil observasi, analisis laboratorium, simulasi virtual, desain dan pekerjaan studio lainnya maka dapat disimpulkan bahwa kegagalan Retaining Wall di PT. MHB disebabkan oleh gerakan tanah yang terjadi dalam dua phase. Phase I adalah ketika hujan terjadi dan menyebakan naiknya nilai $\gamma$ dari $1,75 \mathrm{~kg} / \mathrm{cm}^{3}$ menjadi $\gamma_{\text {sat }}=2,02$ $\mathrm{kg} / \mathrm{cm}^{3}$ Sudut Geser dalam $\phi$ mendekati $0^{\circ}$ 
dan kohesi c mendekati $0 \mathrm{~kg} / \mathrm{cm}^{2}$ dimana kandungan air mencapai $\mathrm{w}=56 \%$, sehingga batas cair tanah terlampaui dan terjadi liquifaction dikarenakan tanah adalah tanah urukan tanpa dipadatkan, sehingga terjadi soil creep yang mendorong retaining wall runtuh. Phase II terjadi setelah retaining wall runtuh dikarenakan tanah sudah mulai menujuk kestimbangan akibat longsor phase I dan tanah mulai padat secara alami, namun setelah musim hujan berikutnya $\gamma$ tanah yang meningkat tanah menjadi cukup berat ditambah beban permukaan yang membuat momen pendorong lebih besar dari momen penahan. Longsor ini terjadi pada waktu tanah masih memiliki cohesi atau cohesi $c \neq 0$ sehingga terjadi longsoran guling yang dicirikan bidang longsor yang berbentuk circular baik nampak dari atas maupun dari samping.

\section{Saran}

Supaya dipastikan tidak ada kegagalan retaining wall maka perlu dilakukan:

a. Desain retaining wall secara teknis yang menerapkan subdrain untuk menghindari kenaikan kadar air (w) sampai dengan kondisi batas cair dari backfills.

b. Desain retaing wall perlu diuji dengan simulasi komputer untuk memastikan kondisi faktor kemaanan lebih dari 1.5 .

\section{Daftar Pustaka}

Abramson L. W, Thomas S. Lee, Sunil Sharma, Glenn m Boyce, 1996, Slope Stability and Stabilization Methods, wiley-Interscience Publication John Willey \& Sons, Inc. 629 pages.

Bishop, A.W. and Morgenstern, N., 1960. Stability coefficients for earth slopes.

Geotechnique, Vol. 10, No. 4, pp. 164 169.

Hang Lin,Wenwen Zhong, Wei Xiong, and Wenyu Tang, 2014 "Slope Stability
Analysis Using Limit Equilibrium

Method in Nonlinear Criterion" Hindawi Publishing Corporation Scientific World Journal Volume 2014, Article ID

206062, 7 pages

http://dx.doi.org/10.1155/2014/206062

Hoek, E., Bray, J.W., 1974. Rock Slope Engineering - Appendix 3. Published for the Institute of Mining and Metallurgy., pp. $352-354$.

Karnawati, 2002, Pengenalan Daerah Rentan Gerakan Tanah dan Upaya Mitigasinya, Makalah Seminar Nasional Mitigasi Bencana Alam Tanah Longsor, Semarang 11 April 2002. Pusat Studi Kebumian Lembaga Penelitian Universitas Diponegoro.

Morgenstern, N.R., and Price, V.E., 1965. The Analysis of the Stability of General Slip Surfaces. Geotechnique, Vol. 15, pp. 79-93.

Totok Sulistyo, 2013, Penentuan Faktor Keamanan pada Lereng Facies Delta. Jurnal Ilmiah Teknologi Terpadu (JTT) Vol. 1 No. 1 ISSN 2338 - 6649.

Totok Sulistyo, 2012, Study On Slope Stability In Vulnerable Landslide Area For Evaluation Of General City Spatial Arrangement Plan In South Balikpapan, Journal Ilmiah Poltekba. No. 1. Vol.4.

Whitlow R, 1983, Basic Soil Mechanics, Contruction Press, London, New York, 439 pages.

2000, Keputusan

Menteri Energi dan Sumber Daya Mineral Nomor 1452 K/10/MEM/2000 Tentang Pedoman Teknis Penyelenggaraan Tugas Pemerintah di Bidang Inventarisasi Sumberdaya Mineral dan Energi, Penyusunan Peta Geologi, dan Pemetaan Zona Kerentanan Gerakan Tanah.

, 2002, Kajian Geologi untuk Evaluasi Penataan Wilayah dan Pengembangan Kota Balikpapan, BAPPEDA Balikpapan. 